\title{
INSTITUCIONES Y PRAXEOLOGÍA. UN ANÁLISIS COMPARADO
}

\author{
JOSÉ CARLOS HERRÁN ALONSO*
}

Mises sitúa la acción intencional en el centro de todo su desarrollo teórico económico. Al utilizar el término «acción humana» ${ }^{1}$ como sinónimo de acción intencional emprendida por el ser humano tras un cálculo racional entre medios y fines subjetivamente considerados, Mises contribuye a edificar sobre sólidas bases un entramado capaz de soportar el envite epistemológico y metodológico propio de otras corrientes de pensamiento económico.

En este trabajo, más allá del comentario procedente, cuando de lo que se trata es de comparar la entidad de la acción intencional con la naturaleza de las instituciones sociales, pretendemos definir ámbitos y conceptos que mejoren la comprensión respecto a los distintos objetos de estudio de que se trata. Adelantamos ya nuestra impresión sobre el aparente dualismo metodológico que divide acción humana e instituciones sociales, considerando que en absoluto la duplicidad de métodos niega o merma la capacidad explicativa de cada teoría.

Praxeología y método histórico evolutivo no son sino recursos metodológicos compatibles y necesariamente integrados dentro del estudio social. La psicología, partiendo de los fundamentos descritos por Hayek en El Orden Sensorial, ${ }^{2}$ será la tercera pata del banco epistemológico capaz de plantear razonamientos rigurosos y próximos a la verdad científica.

A continuación trazaremos los extremos más importantes a fin de presentar una explicación suficiente y coherente de las relaciones más importantes entre Acción intencional, o Acción humana, y Conducta: la praxeología, como estructura lógico-formal,

\footnotetext{
* Master Oficial en Economía de la Escuela Austriaca y Doctor en Economía. Universidad Rey Juan Carlos.

1 Véase Mises (2004).

2 Hayek (2004).
} 
y el contenido normativo y las reglas de conducta, con su complejidad e indispensable integración disciplinar.

\section{I \\ LA ACCIÓN HUMANA}

Afirmar que el hombre actúa de manera consciente, persiguiendo fines, sirviéndose de medios, no permite negación sin caer en flagrante contradicción. El axioma de la acción resulta irreductible, fundante y básico, por ese motivo. A partir del mismo cabe inferir deductivamente una serie de consecuencias lógicas a modo de leyes de tendencia coherentes con el principio de la acción intencional. Para que la explicación sea rigurosa debemos aportar algunos elementos más. Primero, el Hombre es racional en todas las decisiones que adopta. De acuerdo con la definición particular que nos proporciona Mises de la racionalidad: ${ }^{3}$ la entendida de alguna manera como aquella capacidad intelectiva al servicio del ser humano que le permite plantearse fines $u$ objetivos así como los medios subjetivamente considerados como idóneos para lograrlos.

El subjetivismo nos permite incorporar un elemento indispensable para nuestra argumentación: tanto fines como medios son subjetivamente considerados por cada actor. Sus decisiones serán siempre racionales por este hecho. Además, en cuanto al valor de los fines o la utilidad de los medios, nos parece posible afirmar que la subjetividad lo condiciona directamente a la escala valorativa personal y dinámica del sujeto, siendo el valor aquella apreciación subjetiva más o menos intensa que el actor da al fin, y la utilidad, por consiguiente, la apreciación subjetiva que el actor concede al medio en función del valor que para él tiene el fin perseguido. El ser humano, en este orden de cosas, está dotado de la capacidad de descubrir o crear la información y el conocimiento relevantes que le permitan definir nuevos medios para fines previos, así como nuevos fines, que en todo

3 Mises (2004), pp. 24-27. 
momento surgen de la nada redefiniendo su escala valorativa. La función empresarial del individuo contribuye a resolver la escasez de bienes como las instituciones sociales lo hacen con la incertidumbre inerradicable.

Mises plantea la Praxeología como la ciencia de la acción humana, en términos formales, sustentada sobre el axioma irreductible de la acción intencional, desplegando un entramado teórico capaz de descubrir leyes de tendencia a fin de explicar el comportamiento humano intencional. Esta ciencia maneja un método lógico deductivo, genético causal, que resuelve por fin la controversia metodológica dentro del estudio de las ciencias económicas. Si bien todo esto es cierto, no debe distraernos ni obcecarnos en conclusiones extensivas con riesgo de convertirse en falaces. La praxeología misiana trata sobre la acción intencional en términos formales.

Su perfección, siempre que los razonamientos estén bien construidos y respeten el axioma de la acción, no dirá más de lo que cualquier ciencia formal o lógica sea capaz. No es incluible la psicología, y en ningún momento parece la intención de Mises, dentro del ámbito praxeológico, como tampoco será posible analizar la entidad institucional exclusivamente desde sus planteamientos. La praxeología define la ciencia económica, en sentido estricto, apriorístico y formal. Es suficiente y rigurosa, pero ni debe extenderse de forma arbitraria ni lleva en su razón de ser semejante pretensión.

La conducta humana o el comportamiento institucional no generan epistemológicamente ni negación ni contradicción con la Praxeología, sencillamente exigen otro método y comprensión, en los términos que veremos a continuación.

II

INSTITUCIONES SOCIALES

Como resultado de la acción y la interacción (intercambio) humanos, surgen las instituciones, nunca como una definición a priori de conocimiento e información a fin de aminorar la incertidumbre inerradicable que acecha al individuo en su toma de 
decisiones racionales, sino como un continente relativamente estable de conocimiento e información básicamente inarticulable, de tipo tácito y práctico. Este contenido no forma parte de ningún acto de planificación integral sino que resulta de la intervención de numerosos actores en tiempos y lugares diversos.

El tipo de hábitos y pautas que encierran las instituciones sociales responden a una categoría compleja de conocimiento que escapa en gran medida del control consciente, no puede plantearse de la nada fruto de un acto intencional o deliberado, no forma parte del ámbito de la acción intencional, si bien es cierto emana de ella, como de la mera interacción, eso sí, en un tiempo distinto al que pudiéramos considerar como praxeológico. Se trata de un tiempo extenso, histórico y extremadamente complejo.

Toda institución social representa frente al observador atento regularidades dinámicas pero ciertamente estables que podrían definirse sin mayor problema como reglas. Estas reglas sociales, interactivas, por las que el sujeto intercambia y/o interactúa de acuerdo con un conocimiento tácito pero consistente capaz de guiar su conducta, pertenecen al ámbito que Hayek denominó de reglas de recta o mera conducta. ${ }^{4}$ De estas reglas, aquellas que acaban disciplinando de forma más expresa, concretando su contenido en enunciados preceptivos relativamente discernibles, adquieren la condición de normas, en su definición típica e igualmente apriorística y dogmática que la utilizada en la praxeología para la Acción Humana.

En realidad estas normas de las que hablamos no son sino un conjunto indeterminado de reglas de mera conducta, que adaptando diferentes aspectos y comprendiendo diversos ámbitos, traman una red capaz de generar un orden de acciones estable. Proceder a la definición sustantiva institucional puede inducir errores importantes pero, aun así, parece indispensable a fin de articular nuestro conocimiento y plantear alternativas teóricas y conceptuales sobre el complejo amasijo de regularidades institucionales. Mercado, dinero, moral o Derecho, portan en su interior un contenido común de reglas, si bien los dos últimos

4 Véase Hayek (2006a, 2006b). 
adquieren en su definición una calidad normativa singular, infiltrada, en todo caso, dentro del resto de instituciones sociales, como muestra de la sustancia común que las forma.

Estudiar las instituciones sociales exige incorporar la distinción de los tres niveles de análisis: acción humana, relaciones de intercambio e instituciones sociales evolutivas. ${ }^{5}$ Primero porque debemos mantener la rigurosidad que inspira la Praxeología. Segundo porque en la comprensión del contenido institucional y la conducta humana deben tenerse en cuenta el aspecto social, la interacción individual como muestra de la persecución de fines particulares por parte de cada actor, así como la paulatina constitución de ámbitos de disponibilidad o dominio efectivos reconocidos con mayor o menor generalidad y abstracción a favor de los sujetos intervinientes dentro del orden general de acciones.

Instituciones y su contenido son históricos, pero también una manifestación de la naturaleza humana. El estudio histórico compositivo ${ }^{6}$ resulta indispensable para plantear un panorama general de análisis. Este esfuerzo intelectual se verá completado por otras disciplinas y formas de investigación y descubrimiento teórico, tal y como veremos en el siguiente apartado.

III

\section{CONDUCTA Y ACCIÓN}

Definimos conducta tal y como lo hace la RAE, como la manera con que los hombres se comportan en sus vidas y acciones. La conducta se aprecia en la acción, pero no es la acción misma. La acción humana es intencional, diferenciándola así de todo acto reflejo o impulsivo incontrolado por la consciencia. Que el mero funcionamiento de nuestros órganos, la digestión o circulación, no sean acciones humanas (intencionales) implica que en la conceptualización de aquella, más allá del apriorismo praxeológico, incluyamos algunos elementos.

\footnotetext{
${ }^{5}$ Martínez (2006), segunda parte, pp. 143-194.

6 Martínez (2006), capítulo IX, pp. 163-181.
} 
Una acción humana, intencional, persiguiendo fines, valorados subjetivamente, adoptando medios subjetivamente considerados como idóneos para alcanzarlos, no conlleva en absoluto que toda la decisión sea plenamente consciente, todo el conocimiento expreso o que la conducta resultante pueda explicarse íntegramente en términos praxeológicos. Mises intuyó unos presupuestos de la acción, causalidades que vertebran nuestra estructura cognitiva dotando a la mente humana de las herramientas suficientes para trazar de manera bastante la inteligibilidad y perceptibilidad del individuo. ${ }^{7}$ Causas-efecto que Hayek denominaría teorías, como partes integrantes de redes, memorias o mapas sensoriales generadores de un orden cognitivo distinto al orden físico. ${ }^{8}$ Que el hombre actúe y no quepa negarse dicho extremo, y que de ahí se afirme la Acción Humana como axioma irreductible del que deducir lógicamente una serie de leyes de tendencia, universales y atemporales, no implica en absoluto que desconozcamos cuál es la entidad de la mente humana.

Si los elementos básicos del orden sensorial figuran en el esquema misiano como presupuestos de la acción intencional, no tiene sentido obviar que dentro de la mera estructura cognitiva del ser humano figuran contenidos reglados propios de la conducta (más allá de las funciones básicas perceptivas o ejecutivas), de esa forma que tiene el Hombre de comportarse en su vida y acciones. Mantenemos en todo momento la vigencia de las conclusiones praxeológicas, así como aseveramos la necesidad de un método distinto al genético-causal para apreciar y analizar las instituciones históricas, o aducimos que también resulta indispensable integrar otro tipo de indagaciones, jurídico-formales, filosóficas o ético-teóricas, para mejorar el resultado de nuestro proceso de investigación. Siendo así debemos incorporar, como parece razonable, los descubrimientos realizados en el estudio psicológico, de la cognición y sus distintas funciones.

Todo lo explicado hasta aquí como requisito previo para que podamos dar el paso que sigue: distinguir entre los contenidos

\footnotetext{
7 Véase Hayek (2007).

8 Véase Hayek (2004).
} 
reglados de conducta que disciplinan nuestro comportamiento, interacción y mera acción intencional, en función de la intensidad o superficialidad con la que contribuyen a la formación de la estructura cognitiva.

Nos remitimos a las explicaciones dadas en otros lugares ${ }^{9}$ para concluir que la mente humana interioriza con mayor o menor intensidad determinados contenidos normativos a fin de disciplinar la conducta. En la medida que dicho conocimiento, incorporado gracias a procesos de transmisión y aprendizaje en gran medida tácitos, aunque también expresos (no tanto por lo explícito de aquello que se muestra sino por el entramado tácito que lo hace sostenible y eficiente), discipline la conducta de forma efectiva e inconsciente o semiinconsciente, podremos llegar a incluir dichas reglas de mera conducta dentro la estructura cognitiva del actor, siendo, en términos praxeológicos, presupuestos genuinos de la acción intencional.

Que el actor sea consciente de cierto tipo de conocimiento e información relevantes para su acción, a fin de decidir qué curso ejecutivo emprender, o la idoneidad de los medios elegidos para tal empeño (subjetivamente apreciados o estimados en cuanto a su utilidad respecto al fin), no implica que en su intencionalidad no guarde cierto conocimiento tácito, del que es semiinconsciente por no saberlo articular, componer o expresar a través del lenguaje. Ese límite difuso entre lo que gobierna la acción de manera profunda, intensa, disciplinando la conducta a modo de piloto automático mental, y el conocimiento práctico relevante que incorporamos en la decisión ejecutiva, no debe llevarnos a considerar que la praxeología pueda absorber lo que pertenece a un ámbito de estudio típicamente psicológico, o que por esta incapacidad, debamos descartar su rigurosidad formal o su condición básica para la teorización económica.

9 Herrán, J.C. (2009). 
El debate metodológico entre monismo y dualismo en cuanto a las diferencias esenciales que existen entre las ciencias económicas y las ciencias naturales, demostró la coherencia y superioridad de los argumentos planteados por los miembros de la Escuela Austriaca de Economía ${ }^{10}$. No es lo mismo estudiar ideas o la acción del Hombre que hacer lo propio con objetos tangibles. Las regularidades del orden natural no son asimilables a las que puedan existir en el orden social.

El análisis sobre fenómenos diversos exige distintos métodos, de ahí que para construir una teoría sobre la acción intencional del individuo no sea válido el método empleado en las ciencias empíricas o naturales. Mises concluyó en su praxeología que a partir del axioma de la acción humana, irreductible, cabe deducir lógicamente, a través de un razonamiento de tipo genético causal, leyes de tendencia universales y atemporales, capaces de explicar en términos formales el comportamiento del Hombre.

Sabemos que si bien esto es cierto no debe olvidarse que el ser humano no puede reducirse a un aspecto formal y perfecto, sino que comporta una complejidad y diversidad imposibles de explicar exclusivamente a través de la praxeología. Para comprender la conducta humana y percatarse de los presupuestos de la acción intencional que analiza formalmente la praxeología (fundamento de toda teoría económica) debemos incorporar los hallazgos conseguidos en el campo de la psicología o la investigación histórico evolutiva de las instituciones sociales que ayudan al individuo a aminorar la incertidumbre que lo acecha en cada una de sus decisiones. Para ello, como se ha visto en la explicación precedente, importa qué información o conocimiento permanece en niveles de interiorización tales como para considerarlos presupuestos o determinantes de la acción, y cuáles no.

La acción humana trata sobre los fines y los medios conscientes perseguidos y adoptados por el individuo. De ella se

10 Véase Menger (1883 [2007]). 
concluye con suficiencia y rigor científicos la teoría económica genuina, aquella que no confunde objetos de estudio y acierta el método de investigación. Dentro de los presupuestos de la acción resulta obligado comprender la conducta humana profundizando en la indagación psicológica o en el estudio de las reglas que gobiernan el comportamiento.

Cuando hablamos de presupuestos de la acción en sentido estricto nos referimos a aquellas reglas perceptivas y ejecutivas que forman parte de la estructura cognitiva del ser humano, a modo de instrumental indispensable para conocer, comprender y decidir. Pero hay algo más, una subclase de reglas que influyen con idéntica determinación en la conducta efectiva del agente: las reglas de mera conducta. Es aquí donde debemos analizar qué contenidos son interiorizados con mayor o menor intensidad, o dicho de otro modo, qué reglas operan de manera inconsciente definiendo el comportamiento del sujeto.

El estudio histórico compositivo, o evolutivo, de los contenidos normativos efectivos, se reduce a aquel conocimiento explicitado en forma de instituciones sociales relativamente articuladas. En realidad la aparente consciencia sobre determinados contenidos no debe hacernos creer que todo el conocimiento relevante permanece accesible a nosotros, sino todo lo contrario. Que podamos explicitar parte del mismo lo único que implica es que sigue existiendo una cantidad de conocimiento tácito muy superior al que seamos capaces de concebir o manipular mentalmente. Con estas ideas claras parece sencillo apreciar en el individuo la capacidad para interiorizar con más o menos intensidad tanto conocimiento tácito como expreso, o dicho de otro modo, en la superficie de su disciplina de conducta, o totalmente fuera de ella, permanecen tanto aspectos tácitos como expresos. Afinando aún más el argumento, todo individuo reproduce una conducta disciplinada, lo que varía es el conocimiento específico que caracteriza semejante disciplina, además de la intensidad con que se interiorizan determinados elementos, sean tácitos o explícitos.

La acción humana intencional depende de estos presupuestos, que van más allá de los meramente perceptivos y ejecutivos, incorporando aspectos de conducta mentalmente estructurales. A partir de ahí podremos considera el resto del conocimiento parte 
deliberativa de la acción, sujeta a la valoración subjetiva por parte de cada individuo, que adopta racionalmente las decisiones que considera más adecuadas a fin de alcanzar los fines deseados.

Respecto a las reglas que gobiernan la conducta, en este sentido, el sujeto dominaría, por así decirlo, aquellos aspectos expresos que permanecen más superficialmente interiorizados en su mente. Son esos los contenidos normativos sobre los que puede extenderse el cálculo, la oportunidad, el posible fraude o incumplimiento. En la medida que no afecten a aquello que sí discipline su conducta con intensidad y profundidad, serán otros los determinantes que condicionaran su acción. Siendo dueños de su voluntad no podremos hablar de presupuestos de la acción, sino de margen de decisión y sentimiento de responsabilidad o deber moral.

El elemento institucional, en este ámbito, ayuda de manera consciente o semiconsciente a aminorar la incertidumbre inerradicable. Son reforzadas con mecanismos como el miedo al rechazo social, el horror al vacío (por incumplir las normas tradicionales), elementos que caracterizan la personalidad de cada individuo así como otros factores diversos. Sobre ese contenido superficial y explícito resulta posible desplegar el cálculo de expectativas o la conveniencia subjetivamente considerada de la conducta consciente, así como los incentivos para seguir una u otra opción.

Hemos visto tras la explicación de los elementos fundamentales que inciden en la conducta y la acción intencional, que no sólo no supone contradicción alguna incluir en su estudio aspectos ajenos a la praxeología, sino que hacerlo contribuye a afirmar la importancia de ésta en cuanto a la posibilidad de generar una teoría económica rigurosa y cierta. Psicología y análisis histórico compositivo de los contenidos normativos y el conocimiento que abarcan las instituciones sociales, deben sumarse a la praxeología y la teoría económica, siendo, en todo caso, conscientes de los límites de cada una de ellas, como también de los métodos que exige la naturaleza de su objeto de estudio. ${ }^{11}$

11 Se ha tratado de mantener en todo momento el rigor de la propuesta metodológica de Huerta de Soto (1994) - los tres niveles para el estudio de las Ciencias Sociales-, recogida en el artículo Historia Conjetural, Ciencia Económica y Ética Social. 


\section{REFERENCIAS BIBLIOGRÁFICAS}

HAYEK, F.A. von (1952 [2004]): El Orden Sensorial, Unión Editorial, Madrid.

- (1959 [2006a]): Los Fundamentos de la Libertad, Unión Editorial, Madrid.

- $\quad$ (1973, 1976, 1979 [2006b]): Derecho, Legislación y Libertad, 3 vols. Unión Editorial, Madrid.

- (2007): Reglas, Perceptibilidad e Inteligibilidad, Estudios de Filosofía, Política y Economía. Unión Editorial, Madrid. Herrán, J.C. (2009): «Mente, Reglas y Derecho», Instituto Juan de Mariana, http://www.juandemariana.org/comentario/ 3563/mente/reglas/derecho/

Huerta DE Soto, J. (1994): «Historia Conjetural, Ciencia Económica y Ética Social», Estudios de Economía Política, Unión Editorial, Madrid, pp. 105-120.

Martínez, C. (2006): La teoría evolutiva de las instituciones, Unión Editorial, Madrid.

Menger, C. (1883 [2007]): El Método de las Ciencias Sociales, Unión Editorial, Madrid.

Mises, L. von (1949 [2007]): La Acción Humana, Unión Editorial, Madrid (9. edición 2009). 